\title{
Match to family medicine sets record
}

A record $38 \%$ of medical graduates in the 2014 Canadian Residency Matching Service (CaRMS) selected family medicine as their program of choice. Interest in family medicine has been steadily increasing since 2003, and a 20-year record high was set just last year when $36 \%$ of graduates selected the discipline.

Dr. Kathy Lawrence, president of the College of Family Physicians of Canada, says this strong showing is the result of the newly implemented family health teams, more competitive compensation and efforts to inform medical students about family medicine early in their training.

"There's been a lot of work done in medical schools with support from the College on the role of family medicine interest groups and bringing awareness about what the practice of family medicine is actually like," says Lawrence. "So people have had more exposure to family medicine earlier."

The College aims to have $40 \%$ of medical graduates choose family medicine as their first choice discipline; while this year's match edges closer to this number, distribution of practice to rural communities remains a problem.

In the 2014 match, there were 27 unfilled spots in family medicine, which means that $98.2 \%$ of all spots were filled. In 2013, there were 43 unfilled spots.

The most preferred discipline after family medicine was internal medicine, followed by all surgical disciplines combined.

The number of applicants selecting a surgical discipline dropped from 429 in 2013 to 369 this year, with fewer graduates selecting orthopedic surgery, neurosurgery, head and neck surgery, and urology. Recent graduates from these surgical disciplines were among those identified as facing employment difficulties in a report published by the

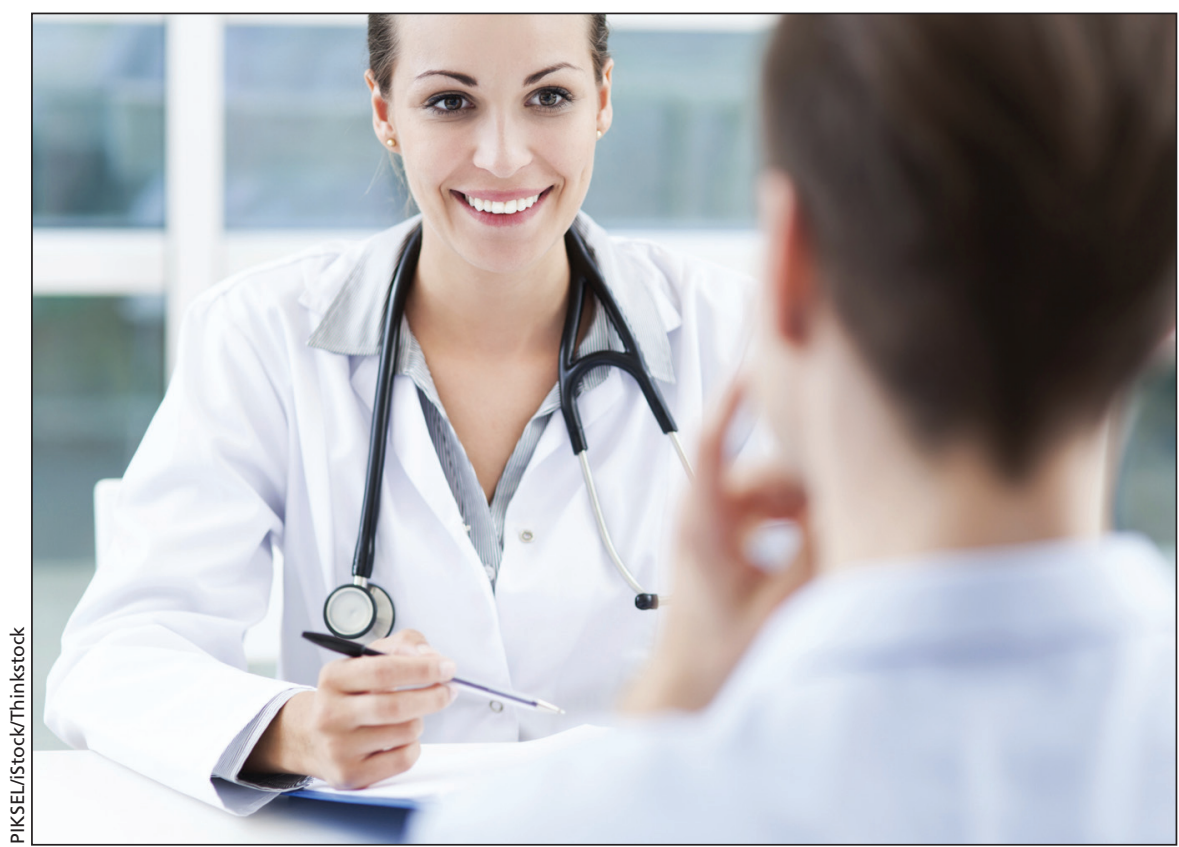

A record 3255 medical graduates matched to residency programs in Canada in 2014.

Royal College of Physicians and Surgeons of Canada in 2013.

Dr. Cecil H. Rorabeck, president of the Royal College, speculates that the report most likely had some influence on students' career choices, but he also warned that the results only document choices at one specific point in time.

"These things can be cyclical," says Rorabeck. "And it's not unusual to see reports such as ours and then 3-4 years from now, we might see another report showing that there's a huge shortage of orthopedic surgeons or neurosurgeons or whatever it might be."

As an orthopedic surgeon himself, Rorabeck hopes that medical graduates interpret the 2013 report in the context of a constantly changing medical environment and pursue careers based on their interests.

In 2014, 3255 medical graduates matched to residency programs in Canada, breaking another record set in 2013. Of this year's applicants, 2779 Canadian graduates matched, representing a success rate of $95.7 \%$, which is congruent with results from previous years. Although a record 2318 international medical graduates (IMGs) participated in the match, only 449 successfully attained a residency position, $10 \%$ lower than last year. CaRMS indicated that 287 of these applicants were Canadians studying abroad, up from 258 in 2013, as detailed in a recent CMAJ news article.

Irving Gold, vice president of CaRMS, acknowledges that IMGs continue to face difficulties with the match; discussions are ongoing among various stakeholders across Canada, including the faculties of medicine, the Canadian Federation of Medical Students and the Fédération médicale étudiante du Québec.

These ongoing discussions are not limited to medical education forums, as evidenced by recent articles in both CMAJ and healthydebate.ca. — Wilson Kwong, Kingston, Ont.

CMAJ 2014. DOI:10.1503/cmaj.109-4844 